\title{
Correlations between Electrical Properties and Process Parameters of Silicon Nitride Films Prepared by Low Temperature $\left(100^{\circ} \mathrm{C}\right)$ Catalytic CVD
}

\author{
Se Myoung Noh* and Wan-Shick Hong***,; \\ *Dept. of Energy and Environmental System Engineering, University of Seoul, Seoul 130-742, Korea \\ **Dept. of Nano Science and Technology, University of Seoul, Seoul 130-742, Korea
}

(Received February 26, 2015; Revised April 2, 2015; Accepted April 7, 2015)

\begin{abstract}
Silicon nitride films were deposited at $100^{\circ} \mathrm{C}$ by using the catalytic chemical vapor deposition technique. The source gas mixing ratio, $\mathrm{R}_{\mathrm{N}}=\left[\mathrm{NH}_{3}\right] /\left[\mathrm{SiH}_{4}\right]$, was varied from 10 to 30, and the hydrogen dilution ratio, $\mathrm{R}_{\mathrm{H}}=\left[\mathrm{H}_{2}\right] /\left[\mathrm{SiH}_{4}\right]$, was varied from 20 to 100. The breakdown field strength reached a maximum value at $R_{N}=20$ and $R_{H}=20$, whereas the resistivity decreased in the same sample. The relative permittivity had a positive correlation with the breakdown field strength. The capacitance-voltage threshold curve showed an asymmetric hysteresis loop, which became more squared as $R_{H}$ increased. The width of the hysteresis window showed a negative correlation with the slope of the transition region, implying that the combined effect of $R_{N}$ and $R_{H}$ overides the interface defects while creating charge storage sites in the bulk region.
\end{abstract}

Key words : Silicon nitride, Catalytic chemical vapor deposition, Low temperature process, Electrical property

\section{Introduction}

W earable devices such as smart goggles and watches, functional suits, and cybernetic skins not only exist in movies and dramas, but are starting to roll out in the consumer market. Such devices require variable form factors, resistance to repeated multi-directional stresses, light weight, and in some cases, durability in harsh environments. Extensive research efforts have been directed to constructing electronic circuitry on flexible backplanes, including organic semiconductors and 2-dimensional materials, but it is still very challenging to fabricate devices that can surpass the current technology utilizing inorganic materials. It is therefore worthwhile to develop a low temperature process to prepare inorganic thin films that can be coated directly on the surfaces of plastic substrates. ${ }^{1)}$ For example, polyethylene naphthalate (PEN), one of the most widely used materials for transparent and flexible substrates, has a glass transition point of $121^{\circ} \mathrm{C} .{ }^{2)}$ Considering the process margin, it would be safe to suppress the film deposition temperature on this material to $100^{\circ} \mathrm{C}$.

Growing reliable dielectric films at low temperatures that can preserve long-term stability and reliability of the current silicon-based technology thus is a considerable challenge. For a low-temperature process for inorganic thin films, great care and attention must be devoted to the

\footnotetext{
${ }^{\dagger}$ Corresponding author : Wan-Shick Hong

E-mail : wshong@uos.ac.kr

Tel : +82-2-6490-5010 Fax : +82-2-6490-5007
}

dielectric films, as these materials serve both as the gate dielectrics for transistors and passivation layers for various devices. The quality of the dielectrics directly influences the device characteristics, such as the threshold voltage shift, hysteresis, power consumption, subthreshold swing, leakage current, and so forth. Silicon nitride $\left(\mathrm{SiN}_{\mathrm{x}}\right)$ is one of the most versatile inorganic materials and can be prepared in a thin film form over a large area. ${ }^{3)}$ Masuda et al. reported that $\mathrm{SiN}_{\mathrm{x}}$ films prepared at temperatures below $300^{\circ} \mathrm{C}$ exhibited low leakage current and a high breakdown electric field as well as conformal step coverage. ${ }^{4)}$

The catalytic chemical vapor deposition (Cat-CVD) technique was developed to overcome technical problems arising in the plasma-enhanced chemical vapor deposition (PECVD) process, such as low efficiency of source gas utilization and plasma damage. ${ }^{5,6)}$ Matsumura reported that the Cat-CVD $\mathrm{SiN}_{\mathrm{x}}$ films have a much smaller concentration of incorporated hydrogen, leading to a denser microstructure and better chemical resistance than their PECVD counterparts, while suppressing the residual stress to a low level. ${ }^{7)}$ CatCVD SiN $/ \mathrm{a}-\mathrm{Si}$ stack films deposited at $250^{\circ} \mathrm{C}$ showed an excellent surface passivation effect for solar cells. ${ }^{8,9)}$

Dilution of the source gas with $\mathrm{H}_{2}$ may enhance the catalytic decomposition efficiency of $\mathrm{NH}_{3}$ and this effect is attributed to reactivation of the catalyst surfaces by $\mathrm{H}$ atoms produced by the catalytic decomposition of $\mathrm{H}_{2}{ }^{10)}$ The resulting $\mathrm{H}$ atoms may also help improve the deposition rate as well as the electrical quality of the $\mathrm{SiN}_{\mathrm{x}}$ films. ${ }^{11)}$ However, to the best of the authors' knowledge, there has been little work reported regarding the correlations between 
electrical properties. In this study, silicon nitride films were prepared by the catalytic CVD (Cat-CVD) technique at a substrate temperature of $100^{\circ} \mathrm{C}$ with $\mathrm{H}_{2}$ dilution of the source gas. Electrical properties, such as the breakdown field strength $\left(\mathrm{E}_{\mathrm{br}}\right)$, bulk resistivity $(\rho)$, and relative permittivity $\left(\varepsilon_{\mathrm{r}}\right)$, were estimated by capacitance-voltage $(\mathrm{C}-\mathrm{V})$ and current-voltage (I-V) measurement techniques, and correlations between these properties were analyzed in conjunction with the process parameters and composition of the $\operatorname{SiN}_{x}$ films.

\section{Experimental Procedure}

Figure 1 schematically illustrates the Cat-CVD apparatus used in this work. A mixture of source gases is introduced to the reactor via the showerhead and the gas molecules are dissociated to radicals by the thermal energy provided by the tungsten filament assembly. The filament was placed at $7 \mathrm{~cm}$ above the substrate and was heated to $1650^{\circ} \mathrm{C}$ electrically. The substrate temperature was maintained at $100^{\circ} \mathrm{C}$ by a custom-designed water cooling system underneath the substrate holder as well as around the filament assembly. The chamber pressure was maintained at 60 mTorr. Silane $\left(\mathrm{SiH}_{4}\right)$, ammonia $\left(\mathrm{NH}_{3}\right)$, and hydrogen $\left(\mathrm{H}_{2}\right)$ were used for the source gas mixture. The mixing ratio of ammonia-to-silane $\left(\mathrm{R}_{\mathrm{N}}=\left[\mathrm{NH}_{3}\right] /\left[\mathrm{SiH}_{4}\right]\right)$ and that of hydrogen-to-silane $\left(\mathrm{R}_{\mathrm{H}}=\right.$ $\left.\left[\mathrm{H}_{2}\right] /\left[\mathrm{SiH}_{4}\right]\right)$ were selected as the main process parameters.

For the C-V measurement, $100 \mathrm{~nm}$-thick $\mathrm{SiN}_{\mathrm{x}}$ layers were grown on silicon wafers, followed by metallization with an aluminum layer, resulting in a metal-insulator-semiconductor (MIS) structure. For Fourier transformation infrared spectroscopy (FTIR) analyses, the films were deposited on low-conductivity silicon wafers. The atomic composition, $[\mathrm{N}] /[\mathrm{Si}]$, inside the deposited film was determined according to the procedure described by Yin et al. ${ }^{12)}$

\section{Results and Discussion}

The atomic composition, [N]/[Si], and the hydrogen content, $[\mathrm{H}]$, were calculated from the FTIR spectra and are plot-

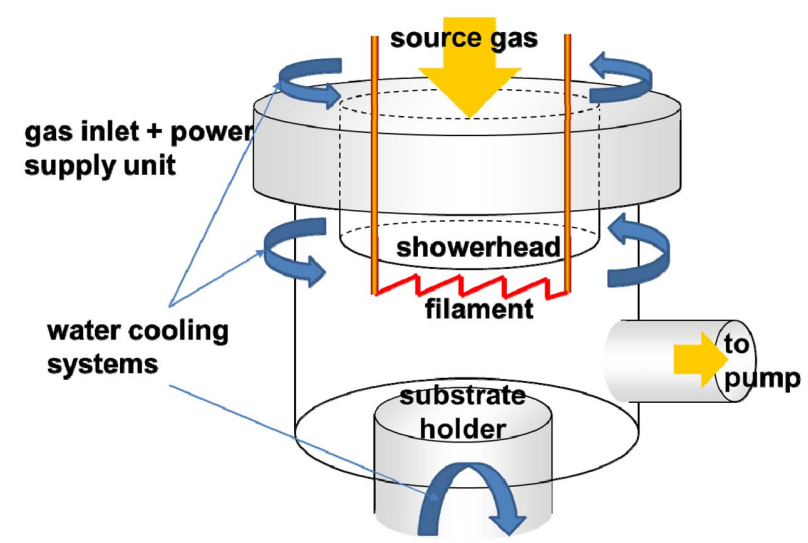

Fig. 1. Schematic of the Cat-CVD reactor for low temperature deposition. ted in Fig. 2 for various $R_{N}$ and $R_{H}$ values in ranges of $10 \leq R_{N} \leq$ 20 , and $10 \leq R_{H} \leq 100$, respectively. The stoichiometric $\mathrm{Si}_{3} \mathrm{~N}_{4}$ corresponds to a value of 1.33. As shown in Fig. 2(a), the atomic composition increased monotonously with $\mathrm{R}_{\mathrm{N}}$. This agrees well with another study on samples prepared at $250^{\circ} \mathrm{C}^{9)}$ The $[\mathrm{N}] /[\mathrm{Si}]$ ratio also increased with $\mathrm{R}_{\mathrm{H}}$. However, as shown in Fig. 2(b), the atomic composition and the hydrogen content exhibit a negative correlation, with a Pearson coefficient of -0.625. According to Ansari et al., high dilution of the source gas with $\mathrm{H}_{2}$ flourishes the catalyst surface with atomic hydrogen, and promotes the decomposition of $\mathrm{NH}_{3}$ molecules into radicals, resulting in an increase of the $[\mathrm{N}] /[\mathrm{Si}]$ ratio inside the growing film. ${ }^{10)}$ As the atomic composition approaches the stoichiometry, the population of dangling bonds, which are the preferential bonding sites for atomic hydrogen, decreases, and an extra supply of $\mathrm{H}_{2}$ may no longer be effective in changing the atomic composition. In addition, the atomic hydrogen abundant in the reactor may combine with the hydrogen atoms residing in the film and evolve as $\mathrm{H}_{2}$ molecules. Therefore, excessive $\mathrm{H}_{2}$ dilution may deplete the atomic hydrogen from the film, influencing the insulating property.

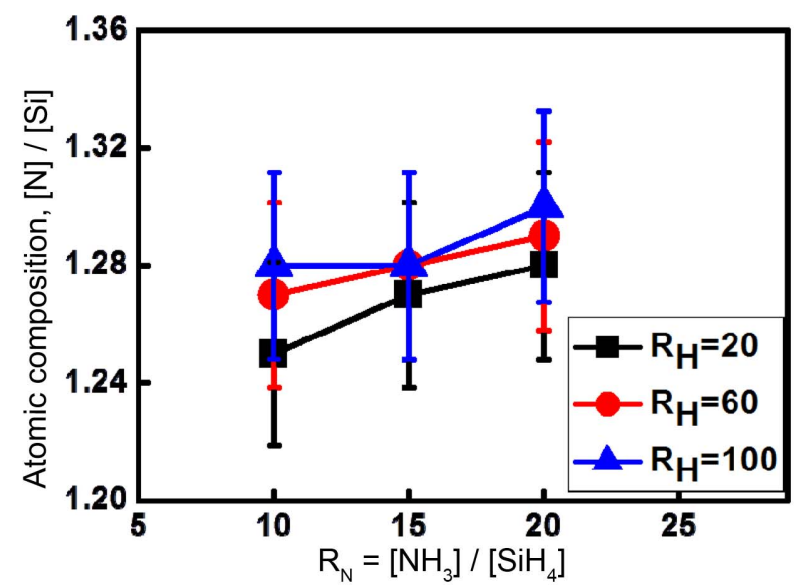

(a)

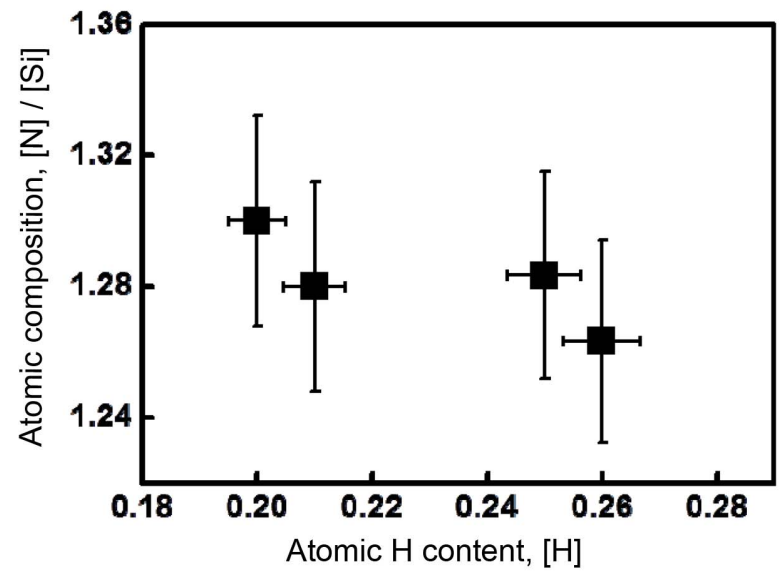

(b)

Fig. 2. Change in the atomic composition, $[\mathrm{N}] /[\mathrm{Si}]$ : (a) as a function of $[H]$, (b) as a function of $R_{\mathrm{N}}$ and $R_{H}$. 
The breakdown field strength $\left(\mathrm{E}_{\mathrm{br}}\right)$ and bulk resistivity $(\rho)$ were estimated from the I-V measurements and are plotted in Fig. 3 for various $R_{N}$ and $R_{H}$ values. As shown in Fig. 3(a), the breakdown field strength showed a maximum value when $R_{\mathrm{N}}=20$ and $R_{H}=20$. At this ratio of the source gas mixture, the atomic composition was estimated to be 1.3 and the relative permittivity $\left(\varepsilon_{\mathrm{r}}\right)$ was measured to be 6.1 . Optimum amounts of $\mathrm{NH}_{3}$ and $\mathrm{H}_{2}$ in the source gas mixture can maximize the $\mathrm{E}_{\mathrm{br}}$ by bringing the film composition close to the stoichiometry, whereas excessive introduction may cause an adverse effect on the $\mathrm{E}_{\mathrm{br}}$.

The effect of $R_{H}$ on the bulk resistivity varied depending on the range of $R_{N}$, as shown in Fig. 3(b). At $R_{N}=20$, the resistivity showed a minimum value and was not increased by $\mathrm{H}_{2}$ dilution. The resistivity did not change noticeably with $\mathrm{H}_{2}$ dilution when $\mathrm{R}_{\mathrm{N}}$ was between 15 and 25 , but changed in a random manner when $R_{N}$ was 10 or 30 . It was difficult to observe a systematic change in $\rho$ with the relative permittivity $\left(\varepsilon_{\mathrm{r}}\right)$, while $\varepsilon_{\mathrm{r}}$ appeared to be related with $\mathrm{E}_{\mathrm{br}}$. Fig. 4 shows the variation of $\varepsilon_{\mathrm{r}}$ as a function of $\mathrm{E}_{\mathrm{br}}$ and of $\rho$. As shown in Fig. 4(a), $\varepsilon_{\mathrm{r}}$ and $\mathrm{E}_{\mathrm{br}}$ had a positive correlation,

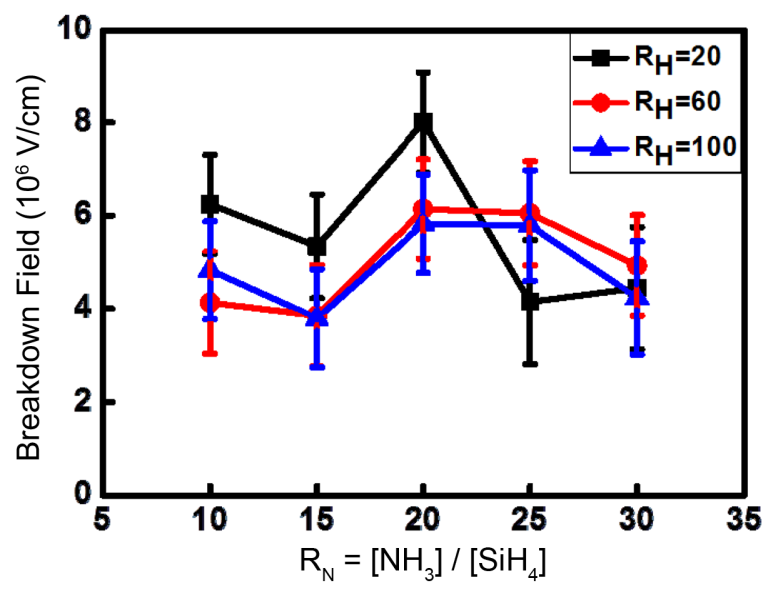

(a)

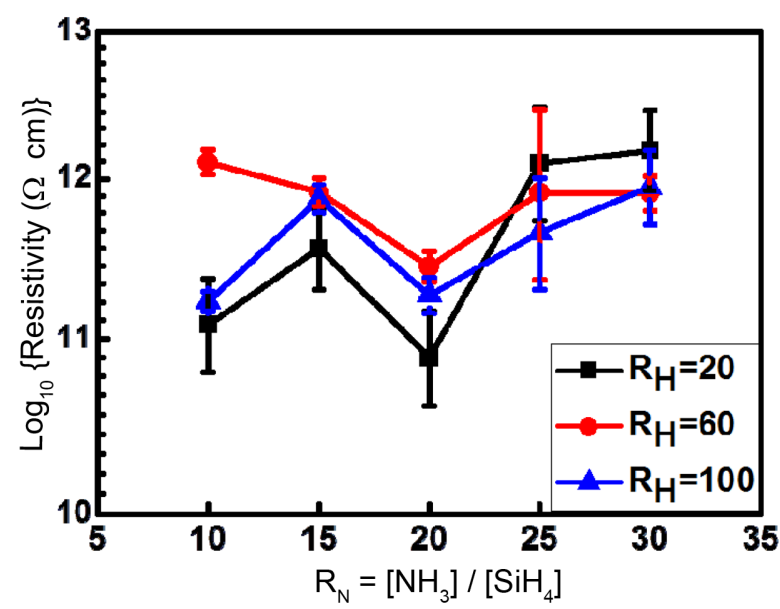

(b)

Fig. 3. Change in electrical properties of low temperature Cat-CVD SiN films with $\mathrm{R}_{\mathrm{N}}$ and $\mathrm{R}_{\mathrm{H}}$ : (a) breakdown field strength, (b) bulk resistivity. with a Pearson coefficient of 0.63 . This correlation can be explained in terms of the formation of microvoids. In hydrogenated silicon oxycarbide films, termination of the Si-O bond network by $-\mathrm{CH}_{3}$ or $-\mathrm{H}$ introduces microvoids around the terminated bonds. ${ }^{13}$ The formation of microvoids is equivalent to alloying under a vacuum, thus decreasing the $\varepsilon_{\mathrm{r}}$ and $\mathrm{E}_{\mathrm{br}}$ values. As it is very likely that microvoids will form in the low-temperature $\mathrm{SiN}_{\mathrm{x}}$ films, both $\varepsilon_{\mathrm{r}}$ and $\mathrm{E}_{\mathrm{br}}$ will be influenced by the microvoids in the same manner and show a positive correlation. However, as shown in Fig. 4(b), the relationship between $\varepsilon_{\mathrm{r}}$ and $\rho$ did not lead to a statistically meaningful description. The $\varepsilon_{\mathrm{r}}$ values also did not show any systematic dependence on $R_{\mathrm{N}}$ or on $R_{H}$.

In order to ascertain the factors influencing the resistivity, the data for $R_{N}=10$ and 20 were extracted from Fig. 3(b) and are re-plotted in Fig. 5 against hydrogen content, $[\mathrm{H}]$, and against the fraction of $\mathrm{Si}-\mathrm{H}$ bonds relative to the total hydrogenated (Si-H and N-H) bonds, respectively. As shown in Fig. 5(a), the resistivity and $[\mathrm{H}]$ have a positive correlation, with a Pearson correlation coefficient of +0.51 . On the

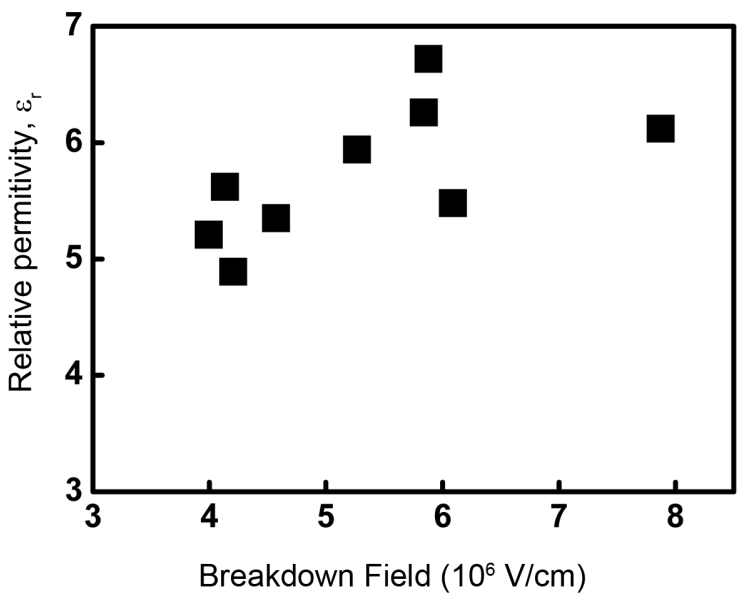

(a)

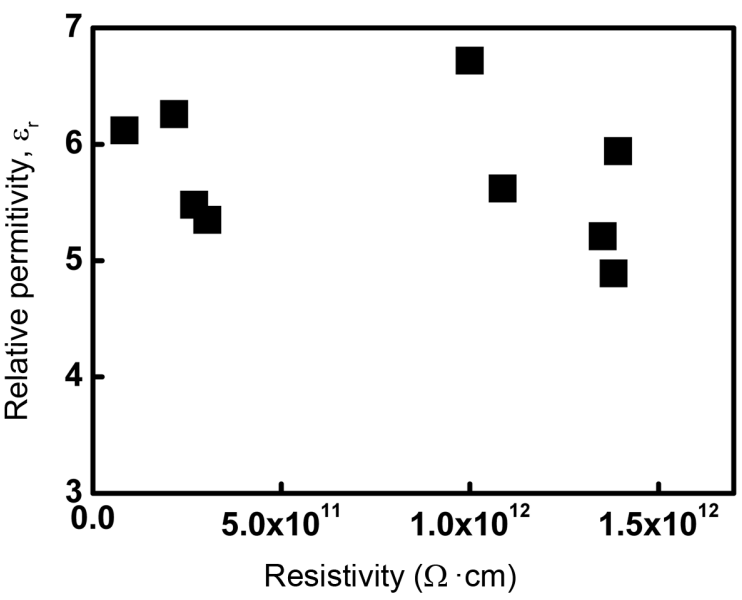

(b)

Fig. 4. Correlations between dielectric and insulating properties: (a) relative permittivity $\left(\varepsilon_{\mathrm{r}}\right)$ vs. breakdown field strength $\left(\mathrm{E}_{\mathrm{br}}\right)$, (b) relative permittivity $\left(\varepsilon_{\mathrm{r}}\right)$ vs. resistivity $(\rho)$. 


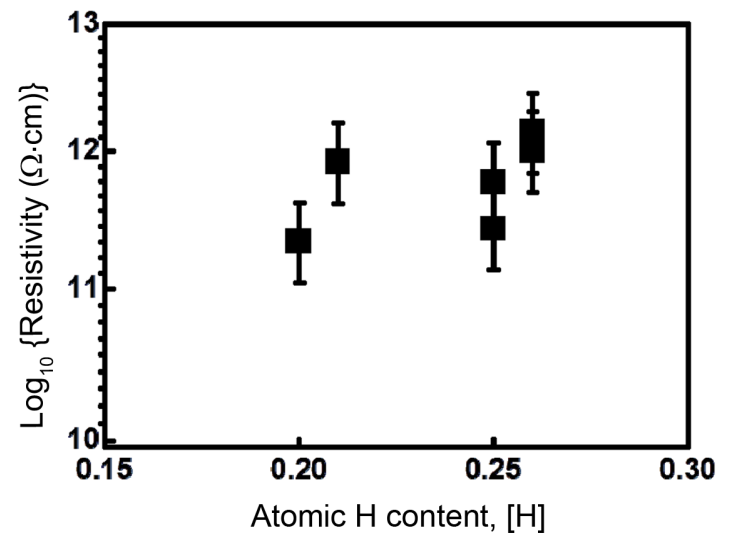

(a)

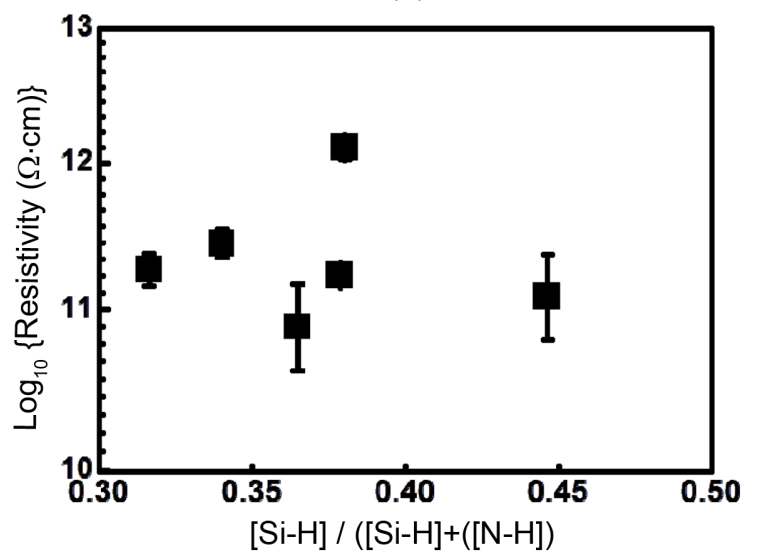

(b)

Fig. 5. Change in the resistivity as a function of (a) hydrogen content, $[\mathrm{H}]$, and (b) the fraction of $\mathrm{Si}-\mathrm{H}$ to the total hydrogenated bonds, $[\mathrm{Si}-\mathrm{H}] /\{[\mathrm{Si}-\mathrm{H}]+[\mathrm{N}-\mathrm{H}]\}$.

other hand, as shown in Fig. 5(b), there was an abrupt increase in resistivity near $[\mathrm{Si}-\mathrm{H}] /\{[\mathrm{Si}-\mathrm{H}]+[\mathrm{N}-\mathrm{H}]\}=0.38$. These results suggest that the electronic passivation of the dangling bonds by the atomic hydrogen is effective in increasing the resistivity, but it is important that the hydrogen atoms combine preferentially with silicon atoms.

Figure 6 depicts the variation of the $\mathrm{C}-\mathrm{V}$ curves with the source gas mixing ratio. The slope at the transition between depletion and accumulation is related to the defects at the insulator-semiconductor interface, while the shift of the threshold voltage is related to the fixed charge inside the insulator. A steeper slope indicates an accordingly lower concentration of interface defects. Also, a smaller threshold shift represents a proportionally lower concentration of bulk defects. ${ }^{14)}$ It should be noted that the $\mathrm{C}-\mathrm{V}$ curves showed a hysteresis behavior with asymmetric transition slopes. During the reverse sweep, i.e., when the gate bias changes from positive to negative, the transition is more gradual than during the forward sweep. This phenomenon is known to be due to the charges trapped at the interface, which affect the discharge process. ${ }^{15)}$ It is seen that the curves in Fig. 6(b), which are for the samples prepared with $R_{\mathrm{N}}=30$,

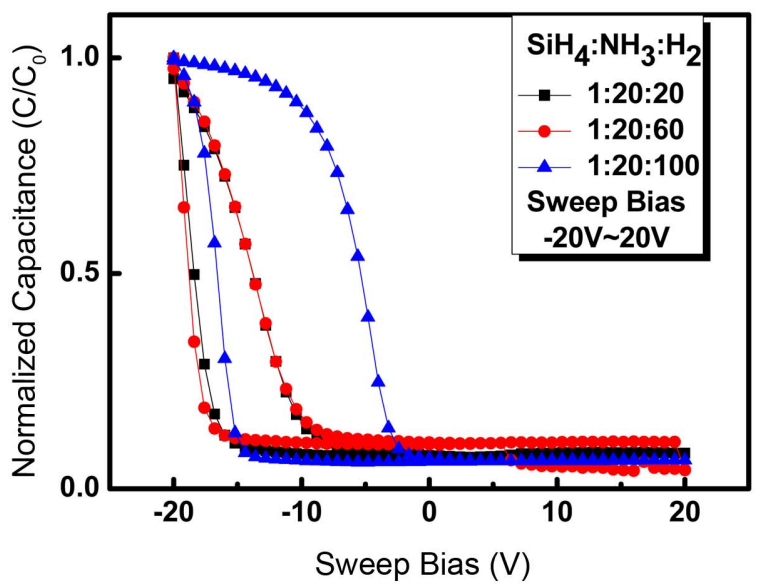

(a)

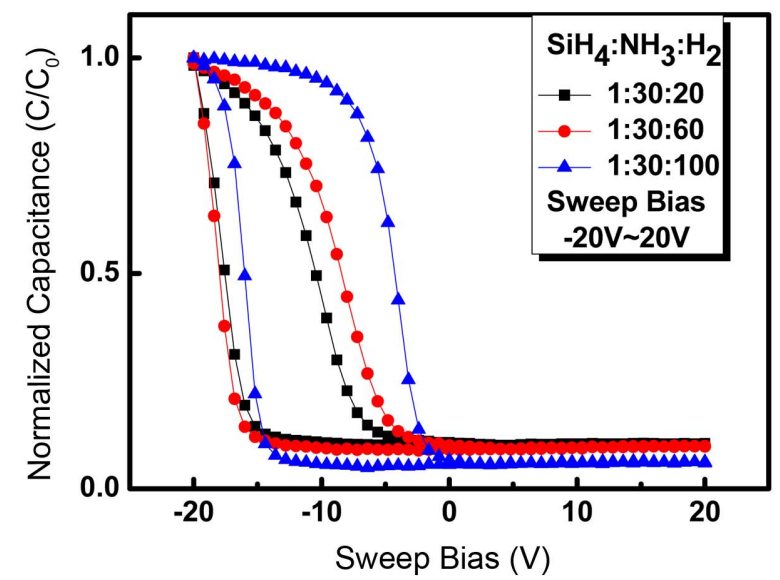

(b)

Fig. 6. Capacitance-voltage (C-V) characteristics: (a) $R_{N}=$ 30 , (b) $\mathrm{R}_{\mathrm{N}}=20$.

exhibited steeper slopes and wider hysteresis loops than those in $6(\mathrm{~b})$, which are for the samples prepared with $R_{\mathrm{N}}=$ 20. Commonly in Figs. 6(a) and 6(b), the transition slope during the reverse sweep became steeper as $R_{H}$ increased. As discussed previously with respect to improving the resistivity, a supply of extra hydrogen will passivate the dangling bonds, which act as traps for the interface charges. The amount of trapped charges that are released during the discharge process hence can be decreased effectively by hydrogen passivation. The increase of the transition slope accompanied an increase in the hysteresis window, $\Delta \mathrm{V}$, which corresponded to the difference in the transition voltage between the forward and the reverse sweep.

The average threshold shift, $-\mathrm{V}_{\mathrm{th}}$, was defined as the bias voltage at the midpoint of the hysteresis loop and is plotted against the threshold slope in Fig. 7. As shown in Fig. 7(a), the slope at the threshold and the extent of the threshold shift toward the negative bias have a negative correlation, with a Pearson coefficient of -0.83 . This suggests that both the interface and the bulk defects are influenced by a common factor. It is known that, when deposited directly on 


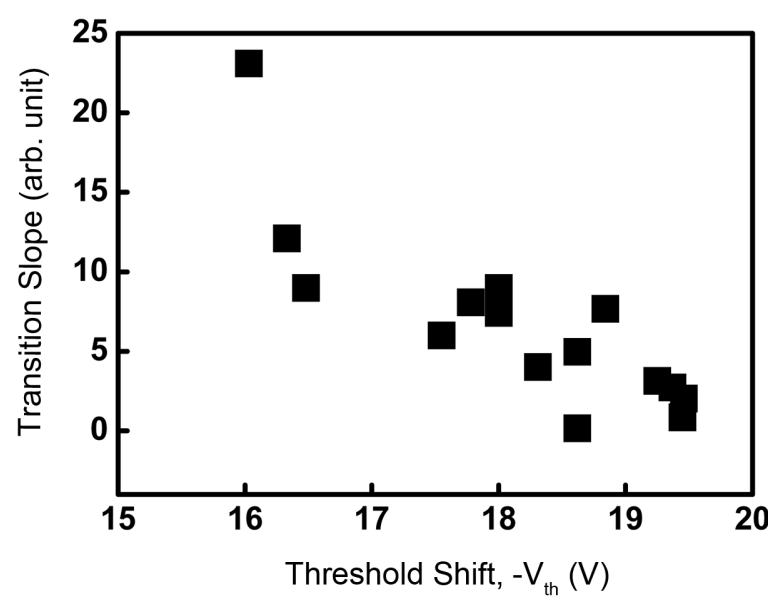

(a)

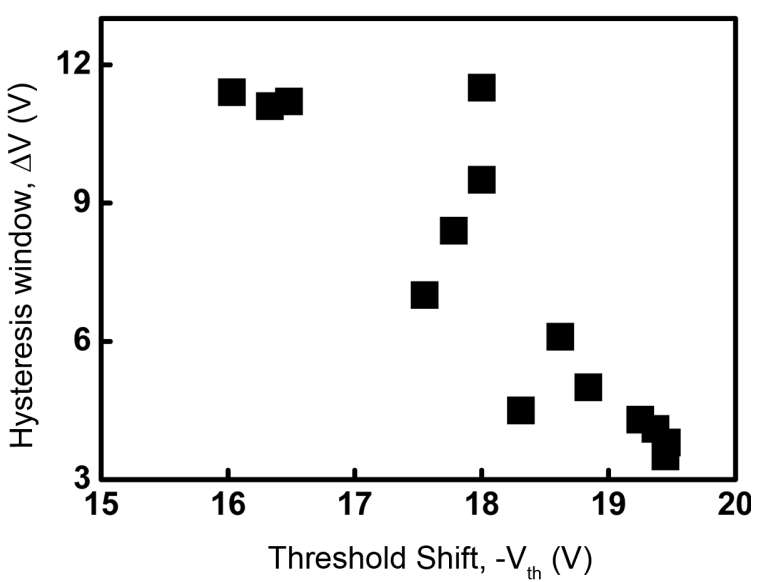

(b)

Fig. 7. Correlations between electrical properties extracted from $\mathrm{C}-\mathrm{V}$ measurements: (a) transition slope vs. threshold shift $\left(-\mathrm{V}_{\mathrm{th}}\right)$, (b) hysteresis window $(\Delta \mathrm{V})$ vs. threshold shift $\left(-\mathrm{V}_{\text {th }}\right)$.

crystalline silicon, $\mathrm{SiN}_{\mathrm{x}}$ films form a rough interface with the substrate. ${ }^{16)}$ A nitridation process on the silicon wafer with $\mathrm{NH}_{3}$ before the film deposition was reported to be effective in minimizing the hysteresis window. ${ }^{4,16)}$ However, the explanation in these references is incomplete in terms of understanding how the width of the hysteresis loop is related to the interface states. Fig. 7(b) shows that the hysteresis window and the threshold shift also have a negative correlation, with a Pearson coefficient of -0.85 . The results presented in Figs. 6 and 7 imply that the combined effects of high $R_{N}$ and high $R_{H}$ reduce the interface defects but create rugged charge storage sites in the bulk region, and that the entire $\mathrm{SiN}_{\mathrm{x}}$ layer can be utilized as a memory element.

\section{Summary}

Correlations between various electrical properties were studied for $\mathrm{SiN}_{\mathrm{x}}$ films prepared at $100^{\circ} \mathrm{C}$ by the Cat-CVD technique. Increasing the hydrogen dilution ratio, $\mathrm{R}_{\mathrm{H}}$, was effective in bringing the atomic composition close to stoichiometry and in minimizing the atomic hydrogen content inside the film. $\mathrm{E}_{\mathrm{br}}$ reached a maximum value of $8 \mathrm{MV} / \mathrm{cm}$ at $R_{N}=20$ and $R_{H}=20$, whereas the resistivity showed a sharp drop for the same sample. The resistivity showed a positive correlation with the content of atomic hydrogen in the film, especially with the hydrogen bonded to silicon atoms. The relative permittivity did not directly depend on either $\mathrm{R}_{\mathrm{N}}$ or $\mathrm{R}_{\mathrm{H}}$, but had a positive correlation with $\mathrm{E}_{\mathrm{br}}$. The $\mathrm{C}-\mathrm{V}$ curves showed asymmetric hysteresis loops, implying a high trap density at the interface of the $\operatorname{SiN}_{x}$ film with the p-type wafer. The stretched-out transition slope during the reverse voltage sweep became steeper as either $R_{\mathrm{N}}$ or $R_{H}$ increased. The width of the hysteresis window showed a negative correlation with the slope of the transition region. These results suggest that the effects of high $R_{\mathrm{N}}$ and high $R_{H}$ together create charge storage sites inside the bulk region of the $\mathrm{SiN}_{\mathrm{x}}$ film and override the influence of the interface defects.

\section{Acknowledgments}

This work was supported by the 2013 Research Fund of the University of Seoul.

\section{REFERENCES}

1. W.M. Yun, J. Jang, S. Nam, Y.J. Jeong, L.H. Kim, S. Park, S.J. Seo, and C.E. Park, "Vacuum Thermally Evaporated Polymeric Zinc Acrylate as an Organic Interlayer of Organic/Inorganic Multilayer Passivation for Flexible Organic Thin-Film Transistors," J. Mater. Chem., 22, 25395-401 (2012).

2. W.S. Wong and A. Salleo, Flexible Electronics: Materials and Applications, pp. 78, Springer Science and Business Media, 2009.

3. J. Jiang and M. Furuta, "Self-Aligned Bottom-Gate In-GaZn-O Thin Film Transistor with Source/Drain Regions Formed by Direct Deposition of Fluorinated Silicon Nitride," IEEE Electron Device Lett., 35 [9] 933-35 (2014).

4. A Masuda, H. Umemoto, and H. Matsumura, "Various Applications of Silicon Nitride by Catalytic Chemical Vapor Deposition for Coating, Passivation and Insulating Films," Thin Solid Films, 501, 149-53 (2006).

5. H. Wiesmann, A.K. Ghosh, T. McMahon, and M. Strongin, "A-Si:H Produced by High-Temperature Thermal Decomposition of Silane," J. Appl. Phys., 50 [5] 3752-54 (1979).

6. H. Matsumura, T. Hasegawa, S. Nishizaki, and K. Ohdaira, "Advantage of Plasma-less Deposition in Cat-CVD to the Performance of Electronic Devices," Thin Solid Films, 519, 4568-70 (2011).

7. H. Matsumura, "Formation of Silicon-Based Thin Films Prepared by Catalytic Chemical Vapor Deposition (CatCVD) Method," Jpn. J. Appl. Phys., 37 [6A] 3175-87 (1998).

8. K. Koyama, K. Ohdaira, and H. Matsumura, "Excellent Passivation Effect of Cat-CVD SiNx/i-a-Si Stack Films on Si Substrates," Thin Solid Films, 519, 4473-75 (2011). 
9. T.C. Thi, K. Koyama, K. Ohdaira, and H. Matsumura, "Passivation Characteristics of $\mathrm{SiN}_{\mathrm{x}} / \mathrm{a}-\mathrm{Si}$ and $\mathrm{SiN}_{\mathrm{x}} / \mathrm{Si}$-rich$\mathrm{SiN}_{\mathrm{x}}$ Stacked Layers," Solar Energy Materials and Solar Cells, 100 169-73 (2012).

10. S.G. Ansari, H. Umemoto, T. Morimoto, K. Yoneyama, A. Izumi, A. Masuda, and H. Matsumura, " $\mathrm{H}_{2}$ Dilution Effect in the Cat-CVD Processes of the $\mathrm{SiH}_{4} / \mathrm{NH}_{3}$ System," Thin Solid Films, 501, 31-34 (2006).

11. J.D. Moschner, J. Schmidt, and R. Hezel, "Catalytic Chemical Vapor Deposition of Silicon Nitride with Strongly Enhanced Deposition Rate," Proceedings of the $19^{\text {th }}$ European Photovoltaic Solar Energy Conference, Paris, France, pp.1082-85 (2004).

12. Z. Yin and F.W.Smith, "Optical Dielectric Function and Infrared Absorption of Hydrogenated Amorphous Silicon Nitride Film,” Phys. Rev. B, 42 [6] 3666-75 (1990).
13. E. Van Besien, A. Singh, Y. Barbarin, P. Verdonck, H.F.W. Dekkers, K. Vanstreels, J.F. de Marneffe, M.R.Baklanov, and S. Van Elshocht, "Low-k a-SiCO:H films as Diffusion Barriers for Advanced Interconnects," Microelectronics Engineering, 120 221-24 (2014).

14. D.A. Niemen, Semiconductor Physics and Devices, pp. 48083, McGraw-Hill, 2003.

15. M. Kuhn, "A Quasi-Static Technique for MOS C-V and Surface State Measurements," Solid State Electron. 13, 873-85 (1970).

16. A. Kikawa, A. Izumi, and H. Matsumura, "Improvements of Electrical Properties and Interface Morphology of SiNx/ Si by Inserting the Nitridation Layer," Dig. Tech. Papers 2003 Int. Workshop Active-Matrix Liquid-Crystal Displays TFT Technologies and Related Materials, Tokyo, Japan, pp. 95-98 (2003). 